\title{
Percutaneous liver biopsy: a cause of hepatic portal venous gas
}

\author{
Uei Pua MBBS
}

$\Lambda$

72-year-old man who was a known carrier of hepatitis B underwent computed tomographic (CT)-guided biopsy of a mass in the liver, which had been detected during routine surveillance. Needle biopsy was performed using a coaxial technique with an 18-gauge Quick-Core biopsy needle set (Cook Medical) (Figure 1A). A CT scan taken immediately after the procedure showed a linear streak of gas at the site of the biopsy. Several gasfilled branching structures that extended to the periphery of the liver were seen, consistent with portal venous gas (Figure 1B, C). As the patient was asymptomatic, treatment was managed conservatively. The patient was discharged in the evening and was well on followup three weeks after the procedure.

Portal venous gas has historically been considered a rare condition associated with mesenteric ischemia and bowel necrosis, with a potentially fatal outcome. Indeed, timely clinical evaluation remains crucial in the appropriate setting. ${ }^{1} \mathrm{Nev}-$ ertheless, it is now known that portal venous gas is not a disease but rather a manifestation with myriad causes. In recent years, benign etiologies have been increasingly recognized, in part because of the rise in use of imaging techniques such as ultrasonography and CT, leading to its increased detection. Among the roster of benign causes, iatrogenic causes are well described. These include lumbar puncture, ${ }^{2}$ double-contrast barium enema, ${ }^{3}$ colonoscopy, ${ }^{4}$ endoscopic sphincterotomy ${ }^{5}$

From the Department of Diagnostic Radiology, Tan Tock Seng Hospital Singapore

CMAJ 2010. DOI:10.1503/cmaj.100325 and radiofrequency ablation. ${ }^{6}$ In our patient, transgression of the portal vein with entry of ambient air during biopsy was the likely cause of portal venous gas. Notably, a common feature among the iatrogenic associations of portal venous gas is the benign clinical course. Therefore, portal venous gas can be managed expectantly when it is incidentally detected in an otherwise asymptomatic patient who has undergone a procedure.

This article has been peer reviewed.

Competing interests: None declared.

\section{REFERENCES}

1. Schindera ST, Triller J, Vock P, et al. Detection of hepatic portal venous gas: its clinical impact and outcome. Emerg Radiol 2006;12:164-70.

2. Karaosmano lu D, Oktar SO, Araç M, et al. Case report: Portal and systemic venous gas in a patient after lumbar puncture. Br J Radiol 2005;78:767-9.

3. Bull MJ, Kaye B. Portal vein gas following double-contrast barium enema. $\mathrm{Br} J$ Radiol 1985;58:1129-30

4. Salyers WJ Jr, Mansour A. Portal venous gas following colonoscopy and small bowel follow-through in a patient with Crohn's disease. Endoscopy 2007;39(Suppl 1):E130.

5. Simmons TC. Hepatic portal venous gas due to endoscopic sphincterotomy. Am J Gastroenterol 1988;83:326-8.

6. Oei T, vanSonnenberg E, Shankar S, et al. Radiofrequency ablation of liver tumors: a new cause of benign portal venous gas. Radiology 2005;237:709-17. 